\title{
Electroceramics VIII-2002 to be Held in August
}

The upcoming Electroceramics VIII-2002 conference of the European Ceramic Society will be the eighth in a series of growing meetings of an interdisciplinary nature that incorporate aspects of chemistry, physics, materials science and technology, and applications of electroceramics. Chaired by Enrico Traversa (University of Rome "Tor Vergata", Italy), the conference will commence August 25-28 in Rome, Italy.

The conference will address basic-science aspects of electroceramics, such as their synthesis, processing, and characterization, with special attention paid to grainboundary engineering. Applications of electroceramics for information technology and for environmental and energy uses will also be stressed. New trends in electroceramics will be emphasized, such as nanostructured materials, nanotechnologies, ceramic microelectromechanical systems, and hybrid and mesoporous materials.

Among the confirmed invited speakers are Tatsumi Ishihara (Oita Uni-

MRS BULLETIN/APRIL 2002 versity, Japan) on "Novel Fast Oxide Ion Conductor and Application for SolidOxide Fuel Cells"; Joachim Maier (MaxPlanck-Institut für Festkörperforschung, Stuttgart) on "Transport in Electroceramics: Micro- and Nanostructural Aspects"; David A. Payne (University of Illinois at Urbana-Champaign) on "Curie-Weiss Analysis of Impedance Boundaries in Ferroelectric Ceramics: Design and Understanding for Improved Dielectrics"; Nasser Peyghambarian (University of Arizona) on "Hybrid Organic-Inorganic Materials for Photonics"; Clément Sanchez (Université Pierre et Marie Curie, Paris) on "Design of Nanostructured Titania and Ceria-Based Materials"; Yasuhiro Shimizu (Nagasaki University, Japan) on "Nanostructured Semiconducting Oxides for Gas-Sensor Applications"; Eric D. Wachsman (University of Florida), topic to be announced; and Anthony R. West (University of Sheffield, U.K.) on "Barrier-Layer Capacitance Effects in Novel Perovskite Materials."

Special sessions of the European
Union's COST 525 Action (Advanced Electroceramics: Grain-Boundary Engineering) and of the EU's Consortium POLECER (Polar Electroceramics) will be offered. Invited speakers from industry are also expected.

The conference will include a manufacturing equipment and publications exhibit and a social program. The proceedings of the conference will be published in a special issue of the Journal of the European Ceramic Society.

The conference is sponsored by the National Research Council of Italy, the Italian Consortium for Science and Technology of Materials, and the University of Rome "Tor Vergata," and is endorsed by the Materials Research Society, the Ceramic Society of Japan, and the American Ceramic Society.

Further information can be accessed at the Web site http://www.uniroma2. it/eventi/electroceramics, or can be requested by e-mail: electroceram@ stc.uniroma2.it. 